\title{
"OLHARES TORTOS" - UM ESTUDO COM MOTORISTAS DE ÔNIBUS DA CIDADE DE PORTO VELHO-RO
}

\section{Vanderleia de Lurdes Dal Castel Schlindwein ${ }^{1}$ \\ Gabrielle Selleri Bezerra²}

Resumo: Este estudo teve como objetivo compreender as dificuldades das mulheres que trabalham como motorista de ônibus na cidade de Porto Velho - RO, suas condições de trabalho e enfrentamentos com os colegas homens. Trata-se de uma pesquisa de cunho qualitativo com cinco mulheres motoristas de onnibus de uma empresa de transporte coletivo da cidade de Porto Velho. Para a realização das entrevistas, foi utilizado um roteiro de questões semiestruturadas. As motoristas descrevem que já vivenciaram situações de discriminação de gênero por parte de passageiros em suas rotinas de trabalho. Por parte dos colegas de trabalho, os preconceitos mostram-se velados nas brincadeiras.

Palavras Chave: trabalho; gênero; motoristas de ônibus.

\begin{abstract}
The goal of this study was to understand the difficulties of women who work as bus drivers in the city of Porto Velho - RO, their working conditions and confrontations with male coworkers. This is a qualitative research with five women, bus drivers from a collective transportation company in the city of Porto Velho. For the interviews, a script of semistructured questions was used. The drivers describe that they have experienced situations of gender discrimination by passengers in their work routines. Regarding to the men coworkers, the prejudices are veiled in jokes.
\end{abstract}

Keywords: work; gender; bus drivers.

\section{Introdução}

As mulheres se deparam com diferentes formas de práticas discriminatórias ao longo da vida, seja no mundo do trabalho, seja em outras esferas sociais, apenas 
por serem mulheres. Estas práticas discriminatórias derivam do preconceito relacionado ao gênero feminino. Segundo Castañeda (2006), são criados papéis e personagens para homens e mulheres, os quais são transmitidos pelos agentes de socialização (pais, escola, meios de comunicação) e reproduzidos e cobrados pela sociedade como um todo. Os estereótipos geralmente estão associados ao que há de similar entre um grupo e são resultado de generalizações muitas vezes incorretas (RODRIGUES, ASSMAR e JABLONSKI, 2015).

Quanto às dificuldades enfrentadas pelas mulheres no contexto do trabalho, os constrangimentos nesse ambiente envolvem discriminação na contratação e nas promoções, falta de apoio no trabalho e nos conflitos entre a carreira e a família e até mesmo a própria linguagem utilizada: as características femininas são usadas para tornar femininos homens ou mulheres considerados indesejáveis e as qualificações ou atributos positivos são, geralmente, expressos numa linguagem masculina. Além disso, carreiras tradicionalmente masculinas exigem muitas horas de trabalho, com dedicação total, o que dificulta assumir diversos papéis de vida, o que normalmente é atribuído à mulher: papel de mãe, de trabalhadora, de esposa e de dona de casa (SAAVEDRA, TAVEIRA e SILVA, 2010).

Portanto, apesar de o espaço para as mulheres nos trabalhos tradicionalmente considerados de homens estar aumentando, estes trabalhos não foram pensados por mulheres nem feitos por elas ou para elas. A vivência masculina permanece o espelho e o contraponto que conduz e determina em parte a busca feminina da construção de uma identidade profissional. Existe um modo de idealização masculinizado (BELLE, 1994).

Bruschini (2007) aponta três contradições em relação à participação da mulher no mercado de trabalho: enquanto ocorre o aumento da participação feminina no mercado de trabalho, existe um nível elevado de desemprego das mulheres e má qualidade do emprego feminino; enquanto as mulheres escolarizadas tem maior acesso às carreiras de prestígio, existe o predomínio do trabalho feminino em atividades informais; enquanto é construída uma nova identidade feminina, voltada tanto para o trabalho quanto para a família, as mulheres ainda são as maiores responsáveis pelo trabalho doméstico e pelos cuidados com os filhos e com a família, o que é característica do modelo tradicional de família e que 
sobrecarrega as mulheres que assumem jornadas de trabalho remunerado.

Em relação à presença feminina no trabalho de motorista de ônibus, Vellozo (2010) concluiu em sua pesquisa realizada com mulheres motoristas de ônibus do Rio de Janeiro, que diferenças biológicas entre homens e mulheres, no sentido ergonômico, tornam-se desvantagens para as mulheres, o que mostra, do ponto de vista das expectativas sociais (associação da atividade de motorista ao gênero masculino), que não era para as mulheres estarem ali, assumindo aquela função. Além disso, a autora também deu ênfase ao acúmulo de tarefas para as mulheres: as mesmas condições adversas do trabalho como motorista para ambos os sexos repercutem de maneira diferente na saúde destas pessoas devido às atribuições distintas de gênero.

Outros estudos corroboram para a importância de discutir as desigualdades de gênero sofridas pelas mulheres no âmbito do trabalho e a maior presença de homens trabalhando como motoristas de ônibus, bem como o preconceito de gênero ao qual as mulheres são submetidas no dia-a-dia de trabalho (ANDRADE, 2016; BRUSCHINI, 2007; ONOZATO e RAMOS, 2001; SAAVEDRA, TAVEIRA e SILVA, 2010; TAVARES, 2010; VELLOZO, 2010). Nesse sentido, buscando aprofundar os dilemas da profissão de motorista de ônibus, este estudo propõe-se a compreender as dificuldades das mulheres que trabalham como motorista de ônibus na cidade de Porto Velho - RO, suas condições de trabalho e os enfrentamentos com os colegas homens.

\section{Método}

A pesquisa foi norteada pelo método qualitativo que, de acordo com Campos (2004), é um método baseado em dados coletados em interações sociais, analisados a partir dos significados que os sujeitos e/ou o pesquisador atribuem ao fato. $O$ pesquisador se propõe a compreender, analisar e interpretar as informações em profundidade.

\section{Participantes}

As participantes do estudo foram cinco funcionárias de uma empresa de transporte coletivo de Porto Velho que trabalham como motoristas de ônibus. Os critérios de inclusão foram ser do sexo feminino, não estar de licença saúde no período da pesquisa e aceitar voluntariamente conceder a entrevista. 
Os primeiros contatos foram realizados com a empresa de transporte coletivo, para obtenção de aprovação para a realização da pesquisa e para solicitar nomes e telefones de motoristas. Após a obtenção destes, foram iniciados os contatos com as motoristas para agendamento das entrevistas, que foram realizadas nos pontos finais dos trajetos dos ônibus, nos horários em que as participantes encerravam seus turnos.

\section{Instrumentos e procedimentos}

O instrumento utilizado no estudo foi uma entrevista com roteiro de questões semiestruturada. Para Triviños (1987) a entrevista semiestruturada tem como característica questionamentos básicos que são apoiados em teorias e hipóteses que se relacionam ao tema da pesquisa.

As questões abordaram temas como: as condições de trabalho das mulheres motoristas de ônibus, preconceitos no caminho das mulheres no trabalho como motorista de ônibus e sobrecarga de trabalho no dia-a-dia das mulheres motoristas.

Como procedimento ético foi apresentado o Termo de Consentimento Livre e Esclarecido (TCLE). Somente após o aceite da motorista foi possível realizar as entrevistas. Para a execução desta, o projeto foi submetido ao Comitê de Ética e por ele aprovado pelo CAAE - 71741217.0.0000.5300. As entrevistas foram gravadas e posteriormente transcritas. Por questões éticas, os nomes das participantes do estudo são fictícios: Zilda, Dandara, Joana, Hipácia e Celina.

A análise das entrevistas foi feita por categorização, que é uma "operação de classificação de elementos constitutivos de um conjunto, por diferenciação e, seguidamente, por reagrupamento" (BARDIN, 1977, p. 117), ou seja, isolam-se os elementos e os reparte procurando impor certa organização. Nesta pesquisa, o agrupamento foi feito segundo critério de categorização por temáticas.

\section{Resultados e Discussão}

As idades das motoristas de ônibus variaram entre 30 e 48 anos; todas têm ao menos um filho; quanto à escolaridade, possuem somente o ensino médio completo. Do estado civil, uma está solteira e quatro delas vivem com seus companheiros. Uma delas trabalha como motorista de ônibus há 10 anos e outra há 
14 anos. As outras três trabalham como motoristas de ônibus há em torno de um ano.

Das condições de trabalho das mulheres motoristas de ônibus, observouse que elas trabalham em condições extenuantes, submetidas ao calor diário conduzindo o ônibus sem climatização. Além disso, ainda relatam as dificuldades no trânsito da cidade:

Tem o excesso do calor né, que às vezes a gente tem muito calor nos dias que a gente tá... você sabe né, é estressante, mas a gente tenta ter um pouquinho de calma né. Se tivesse um climatizado né, seria bem melhor, mas não é, então a gente enfrenta todo dia isso. Sem falar o trânsito né, sem falar as pessoas que fazem coisas erradas na sua frente e você tem que né... tudo isso [Joana].

Às vezes você tá naquele dia muito quente, você já tá cansada, com fome, então essa parte que é um pouco mais complicada. Mas no sentido do trabalho mesmo, isso faz parte e a gente releva [Hipácia].

No estudo de Tavares (2010) com motoristas de ônibus de Uberlândia/MG, foram assinalados vários fatores de estresse no trabalho, como: o trânsito (em que estava englobada a sinalização e as condições de trafegabilidade das vias), os relacionamentos sociais (com passageiros, cobradores e demais colegas de trabalho), a exigência da empresa para o cumprimento de horários, o calor e o ruído dentro do ônibus e a insegurança (risco de acidentes e assaltos).

Onozato e Ramos (2001) assinalam que o trânsito, pelos riscos de acidentes (incluindo atropelamentos e colisões), a falta de sinalização e as condições precárias da pavimentação de ruas e avenidas, são fatores que contribuem para tornar o trabalho de motorista mais desgastante. Os riscos, para Glina (2010, p. 16), provenientes das condições de trabalho, têm efeitos psicológicos e físicos, visto que causam desconforto físico e psíquico. A exposição aos riscos (tais como calor elevado e umidade) vivenciada pelas motoristas de ônibus pode dar origem a experiência de estresse e trazer consequências no desempenho das tarefas.

Um aspecto positivo nos depoimentos foi a segurança com que controlam as cobranças vindas da empresa e a familiaridade adquirida com a atividade de motorista ao longo do tempo. Sobre isto, Sato (2003) diz que ter familiaridade é conhecer e controlar os problemas com regras, máquinas e equipamentos. Cada barulho e movimento diferente são capazes de alertar a trabalhadora sobre o 
andamento normal e anormal do trabalho, possibilitando que ela se prepare para lidar com cada situação diferente que se apresente. Sobre isto, descrevem:

Até que dificuldade eu não tenho não, graças a Deus. A empresa dá condição boa pra gente trabalhar, aí eu não tenho o que reclamar não. Eu trabalho num carro bom, num horário bom, tenho o que reclamar não, graças a Deus [Zilda].

Deixa eu ver se tem alguma... Não sinto... não sinto dificuldade. Talvez pela minha trajetória, pela minha história já passada, eu não tenho nenhuma. Tranquilidade tanto na questão lidar com a máquina, quanto lidar com colega de trabalho, quanto lidar com ser humano, que você tem que ter um certo jogo de cintura. É tranquilo [Celina].

As nossas condições de trabalho hoje, eu acho que desde o começo sempre foi tranquilo. A empresa já é antiga aqui, não no transporte coletivo, mas em outra área. A empresa ela cobra da gente o necessário. Só, no sentido profissional, a gente é cobrada e é o que a empresa precisa. A empresa precisa de profissional. A empresa é grande, muitos funcionários. Então na questão cobrança, acho que normal. Muito normal. Tranquilo [Celina].

É importante destacar que a normalidade apresentada nas falas acima não implica na ausência de sofrimento, mas a possibilidade de as participantes estarem utilizando de mecanismos de defesa para minimizar a percepção do sofrimento causado pelo trabalho. Os mecanismos mais frequentes neste contexto são a negação, sinalizada pela banalização das dificuldades da organização do trabalho, negando-se que a organização do trabalho seja a causa do sofrimento, e a racionalização, que se manifesta em falas que justificam as adversidades do trabalho. Sobre isso, Moraes (2013) adverte que, embora as estratégias defensivas protejam o psiquismo, elas podem conduzir à alienação.

As sobrecargas de trabalho foram definidas pelas motoristas do transporte coletivo de Porto Velho como oriundas, além das condições de trabalho, da conciliação dos turnos de trabalho com outras atividades e de fatores ligados às relações que se estabelecem com os passageiros. Elas explicam:

É meio complicado porque a gente acorda muito cedo. Eu pego $5 \mathrm{~h} 30$ da manhã, acordo $4 \mathrm{~h} 20$. O bom é que a gente larga cedo, 13h30, 14h já estou em casa, é só assim. Mas a gente tem que aprender a dividir as coisas né, trabalhar dos dois lados, inclusive a gente tem família, tem filho né, tem que dividir. Eu e meu marido a gente é bem dividido, até as tarefas de casa [Zilda]. 
O dia a dia não é fácil, é difícil, a gente tem que aguentar muita coisa porque tem muito preconceito tanto de mulher quanto de homem, então é assim. É bom, não é ruim [Dandara].

No período da tarde a gente fica junto, meu filho tá em casa e meu esposo, a gente sai quase todo dia assim, vai pra casa do sogro, pra casa de um tio, dá pra conciliar. Pouquinho mas dá, né. Tem que deixar um tempinho pra tudo, mulher sempre procura deixar um tempinho pra tudo... Pesa um pouquinho, às vezes é cansativo... Mas temos que trabalhar fora né, porque um salário só né, hoje na crise, salário só do esposo não dá [Joana].

Eu não divido. Sou aquela mulher que hoje tem muito. As pesquisas mostram que hoje as mulheres tomaram conta da casa, do trabalho, de tudo, dos filhos. Eu sou esse tipo de mulher. Aquela mulher que faz tudo em casa, que desenvolve sozinha, questão mãe e pai. Eu sou essa pessoa. E em casa é eu, na rua é eu, tudo eu [Celina].

Atualmente, vem sendo construída uma nova identidade feminina, voltada tanto para o trabalho quanto para a familia. Porém, as mulheres, na maioria das famílias, ainda são as maiores responsáveis pelo trabalho doméstico e pelos cuidados com os filhos e com a família, o que é característica do modelo tradicional de familia e que sobrecarrega as mulheres que assumem jornadas de trabalho remunerado (BRUSCHINI, 2007). No estudo de Vellozo (2010) com mulheres motoristas de ônibus, a autora dá ênfase ao acúmulo de tarefas para as mulheres, pois além da atividade de motorista, elas também são responsáveis pelas tarefas domésticas.

No entanto, ainda segundo Vellozo (2010), também vem ocorrendo uma reelaboração da divisão de tarefas domésticas, seja pela delegação de tarefas às outras mulheres que estão ali exercendo um trabalho remunerado (empregadas domésticas, por exemplo), seja com a divisão dos serviços domésticos com o companheiro ou com outros integrantes da família. Este parece ser o cenário das entrevistadas neste estudo.

Outra dimensão de sofrimento no trabalho das motoristas é a vivência de situações de discriminação de gênero que elas enfrentam no trabalho. Estas situações se mostram mais direcionadas a dois sentidos: a crença dos passageiros do não pertencimento das mulheres no lugar de motorista de ônibus e o medo, por causa da crença de que as mulheres têm menos habilidades para dirigir e que, 
portanto, estão colocando as pessoas em perigo. Elas desabafam:

[...] tem homem né, que tem aquele preconceito, ainda chama a gente de barbeira, fala que mulher é para estar em casa pilotando fogão, que não era para dirigir ônibus, mas a maioria é inveja, tem muito homem que não tem capacidade né, aí fala brincando, mas é inveja. A gente tira de letra, finge que não é com a gente [Zilda].

Um homem na hora que ele sobe num ônibus, ele olha para você e fala "nossa, é uma mulher que tá dirigindo!" ou ele fala "ah, não vou nesse ônibus porque é uma mulher que tá dirigindo"... É muito preconceito, no dia a dia é muito, não tem como... qualquer situaçãozinha é motivo [Dandara].

Por mais que falem "ah é mulher que tá ali" e puxa o carro, pra mim não faz diferença, porque se eu tô no ônibus, é porque eu sou capaz de dirigir esse ônibus né, aí não tem porque a pessoa ficar com aquele medo de "porque é mulher vai bater em mim", homem é assim né [Joana].

Às vezes tem passageiro, essa semana teve um passageiro que entrou dentro do ônibus aí ele olhou para mim, passou na roleta, foi lá atrás, voltou, olhou para cobradora e perguntou assim: tu não tem medo não de andar com ela de ônibus? De andar com ela dirigindo não? Tem mulher, homem... chega na porta do ônibus, fala "ih é mulher, não vou não" e não vai. Ou então entra e fala "vamos sentar logo que é mulher dirigindo". Principalmente mulher, o preconceito é maior da parte da mulher. Muitas admiram, me dão parabéns, gostam, mas o preconceito maior assim vem da parte delas também. Homem se não gosta só olha torto e passa, poucos ofendem. Agora a mulher faz questão de falar alguma coisa para você escutar [Hipácia].

A crença de que o lugar de motorista de ônibus não pertence às mulheres pode ser explicada pela reprodução das desigualdades de gênero no mundo do trabalho, as quais estão centradas na noção da mulher como força de trabalho secundária, noção esta que estrutura-se a partir da separação e hierarquização entre as esferas do público e do privado; da produção e da reprodução, como em torno de uma concepção de família nuclear na qual o homem é o principal ou o único provedor, e a mulher é a responsável principal ou exclusiva pela esfera privada (o cuidado doméstico e familiar), ou, no máximo, uma "provedora secundária" (OIT BRASIL, 2010, p. 22).

Nessa visão, a inserção da mulher no mercado de trabalho destoa do papel social que lhe é atribuído e, portanto, será sempre vista como complementar e menos pertencente ao ambiente do trabalho, principalmente quando o ambiente 
de trabalho em discussão é tradicionalmente mais ocupado por homens.

$\bigcirc$ medo, influenciado pelas crenças culturais de inaptidão das mulheres para realizar determinadas atividades, pode ser explicado pela atribuição de características inatas aos sexos masculino e feminino. Para Coutinho (2006) as diferenças estabelecidas entre os sexos, até então, atribuíam à mulher características "naturais" de dependência e subordinação, com reflexos duradouros sobre as relações de gênero, nas quais coube à mulher, por séculos, uma vida privada sob total dependência econômica e emocional do homem. Com o avanço das formas de produção capitalistas, a mulher passou por um processo de inserção no trabalho (p. 34).

A discriminação de gênero no trabalho das mulheres motoristas de ônibus não está, no entanto, presente somente em falas e atitudes de passageiros. Ela também é expressa por parte dos colegas de trabalho homens. Porém, neste caso, os preconceitos mostram-se velados nas brincadeiras. Por mais que as relações sejam boas, por trás das brincadeiras e dos "olhares tortos" (Hipácia), há estigma, preconceito e violência no trabalho.

Aqui é tranquilo... tranquilo. Tem aquelas brincadeirinhas de mau gosto né, mas são tranquilos, eles gostam, admiram. Tem aqueles que não gostam porque quando os passageiros falam assim "ah, aquela mulher dirige melhor do que você", eles não gostam disso, não gostam de ouvir. Mas é tranquilo... Tem aqueles né, com aquele preconceitozinho né, de "ah, porque é mulher" e aí fica comentando né, tem aquele que não gosta, mas também às vezes não admite, não fala, pode não gostar, mas prende pra ele. Mas todos me tratam bem aqui, com respeito [Joana].

É legal, assim, eles me tratam muito bem, eles respeitam. Essa área do ônibus é uma área mais leve pra você trabalhar, os motoristas já respeitam, já tem mais mulheres e não é de agora, desde a usina a mulherada começou a tomar conta né. Aqui e acolá você vê um olhando meio torto, de rabo de olho, mas a gente finge que não tá vendo e vai embora [Hipácia].

Com argumentos de que são apenas piadas, os chistes populares são formas distorcidas de preconceito e discriminação, que encobrem o fraco esquema de análise crítica das pessoas e naturalizam formas de violência contra as mulheres (PAIVA, 2008).

Apesar das diversas expressões de discriminação de gênero, as motoristas 
demonstraram confiança em suas capacidades de assumirem esta ocupação.

Tem muito homem que não tem capacidade né, ai fala brincando, mas é inveja. A gente tira de letra, finge que não é com a gente [Zilda].

A gente faz porque a gente é capaz né... as mesmas coisas que eles fazem, eu faço [Joana].

Aqui e acola você vê um olhando meio torto, de rabo de olho, mas a gente finge que não tá vendo e vai embora [Hipácia].

Por outro lado, algumas das entrevistadas comentaram sobre reações positivas, de admiração, por parte de passageiros, família e amigos.

A gente é muito elogiada né [Zilda].

Muitos veem e gostam, admiram, porque poucas mulheres tem coragem pra dirigir, enfrentar o trânsito, enfrentar o povo falando, principalmente homens. A maior parte me admira muito [Joana].

Família, amigos... acham legal, admiram. Hoje não tá mais tão assim difícil de ver mulher trabalhando... admiram, gostam, elogiam [Hipácia].

Segundo Monteiro e Freitas (2015), a saúde mental no trabalho não está associada à ausência de sofrimento, mas sim à transformação do sofrimento patogênico em sofrimento criativo. Para que a transformação do sofrimento gerado no trabalho, em prazer seja possibilitada, o processo de reconhecimento é um dos fatores fundamentais.

Quando a trabalhadora realiza sua tarefa, possui a expectativa de avaliar o quanto ela é capaz. A certeza da capacidade se dá pelos colegas que a reconhecem, pelos que ocupam uma posição hierarquicamente superior, ou também pelos que usufruem o que é produzido pelo trabalhador ou o serviço oferecido (MONTEIRO e FREITAS, 2015). Este último cenário parece ser o mais presente na rotina das motoristas. Joana reitera este sentimento: "Muitos veem e gostam, admiram, porque poucas mulheres têm coragem para dirigir, enfrentar o trânsito, enfrentar o povo falando, principalmente homens. A maior parte me admira muito" (Joana).

Sobre isso, destaca-se que o reconhecimento é o retorno de todo o investimento objetivo e subjetivo empregado no trabalho; é a retribuição, a contrapartida, e está estreitamente associado à produção de sentido no trabalho. 
Para Clot (2010, p. 285), "a 'retribuição simbólica' e as 'gratificações' que the estão associadas, provenientes da hierarquia, é que tornam 'útil' aquele que trabalha; além disso, o julgamento dos pares outorga o pertencimento ao ofício".

\section{Considerações Finais}

O resultado deste estudo demonstra que as condições de trabalho (a exposição ao calor, a falta de climatização dos ônibus, o trânsito da cidade) e os turnos de trabalho extensos são os principais fatores causadores de estresse na rotina das motoristas do transporte público de Porto Velho-RO. Além disso, as motoristas relatam que os relacionamentos que se estabelecem com os passageiros são fonte de sobrecarga e estresse constante.

Alguns posicionamentos de que situações cotidianas do trabalho são tranquilas, referindo-se às brincadeiras e cobranças por parte da empresa, supõem que haja naturalização das vivências, porque seria penoso o desmantelamento do esquema defensivo e a confrontação com as causas do seu sofrimento no trabalho.

As brincadeiras e as piadas enfrentadas no cotidiano de trabalho das motoristas de ônibus, por passageiros (mulheres e homens) e por colegas de atividade, revelam formas de violências ocultas pelas relações de gênero no trabalho. Já um fator de equilíbrio são os elogios e expressões de admiração que frequentemente recebem dos familiares, passageiros e alguns colegas. Concluise que, o reconhecimento que elas obtêm pode ser um fator de proteção, que as ajuda a transformar possiveis vivencias de sofrimento em prazer.

A partir dos resultados obtidos com este estudo, novos questionamentos surgiram, portanto, convém a realização de mais estudos com este público, para que sejam esclarecidas questões relacionadas às condições desgastantes do trabalho como motorista de ônibus e como estas afetam as motoristas e questões relacionadas aos efeitos da discriminação de gênero no contexto do trabalho e da familia.

\section{Referências}

ANDRADE, T. Mulheres no mercado de trabalho: onde nasce a desigualdade. Brasilia: Consultoria Legislativa da Câmara dos Deputados, 2016.

BARDIN, L. Análise de conteúdo. São Paulo: Edições 70, 1977. 
BELLE, F. Executivas: Quais as diferenças na diferença? In: CHANLAT, Jean-François. $O$ indivíduo na organização: dimensões esquecidas. São Paulo: Editora Atlas, 1994, p. 195-231.

BRUSCHINI, M. C. A. Trabalho e gênero no Brasil nos últimos dez anos. Cadernos de Pesquisa, v. 37, n. 132, p. 537-572, 2007. DOl: http://dx.doi. org/10.1590/S0100-15742007000300003.

CAMPOS, L. F. de L. Métodos e técnicas de pesquisa em psicologia. 3 Ed. Campinas: Editora Alínea, 2004.

CASTAÑEDA, M. O machismo invisível. São Paulo: A Girafa Editora, 2006.

CLOT, Y. Trabalho e poder de agir. Tradução de TEIXEIRA, Guilherme João De Freitas \& VIANNA, Marlene Machado Zica. Belo Horizonte: Fabrefactum, 2010.

COUTINHO, M. L. P. Discriminação no trabalho: mecanismos de combate à discriminação e promoção de igualdade de oportunidades. OIT, Brasilia, 2006. Disponivel em: <http://www.oitbrasil.org.br/sites/default/files/topic/ discrimination/pub/oit_igualdade_racial_05_234.pdf> Acesso em: 2 nov. 2017.

GLINA, D. M. R. Modelos teóricos de estresse e estresse no trabalho e repercussões na saúde do trabalhador. In: GLINA, Débora Miriam Raab \& ROCHA, Lys Esther. Saúde mental no trabalho: da teoria à prática. São Paulo: Roca, 2010, p. 3-30.

MONTEIRO, J. K.; FREITAS, L. G. Trabalho precário e as vivências de prazer - um olhar psicodinâmico. In: MONTEIRO, J. K.; VIEIRA, F. O.; MENDES, A. M. Trabalho e Prazer: teorias, pesquisas e práticas. Curitiba: Juruá Editora, 2015.

MORAES, R. D. Estratégias defensivas. In: VIEIRA, F. O.; MENDES, A. M.; MERLO, A. R. C. Dicionário crítico de gestão e psicodinâmica do trabalho. Curitiba: Juruá Editora, 2013. P. 153-158.

OIT BRASIL. Igualdade de gênero e raça no trabalho: avanços e desafios. Brasilia: OIT, 2010, 216 p. Disponivel em: <http://www.oitbrasil.org.br/ sites/default/files/topic/gender/pub/igualdade_genero_262.pdf>. Acesso em: 29 out. 2017.

ONOZATO, E.; RAMOS, S. P. O estresse na profissão de motorista do transporte coletivo urbano por ônibus. In: I Jornada Científica do CentroOeste de economia e administração, Campo Grande, 2001.

PAIVA, R. Política: palavra feminina. Rio de Janeiro: Mauad X, 2008.

RODRIGUES, A.; ASSMAR, E. M. L. e JABLONSKI, B.. Psicologia Social. 32 Ed. Rio de Janeiro: Editora Vozes, 2015. 
SAAVEDRA, L.; TAVEIRA, M. do C.; SILVA, A. D. A subrepresentatividade das mulheres em áreas tipicamente masculinas: fatores explicativos e pistas para a intervenção. Revista Brasileira de Orientação Profissional, v. 11, n. 1, p. 49-59, 2010. DOI: http://hdl.handle.net/1822/11636.

SATO, L. Subjetividade, saúde mental e LER. In: RUIZ, R. et al. Um mundo sem LER é possível. Del Sur, Montevidéu - Uruguai: UITA, 2003, p. 62-78.

TAVARES, F. de A. Estresse em motoristas de transporte coletivo urbano por ônibus. Dissertação de Mestrado. Uberlândia: Universidade Federal de Uberlândia, 2010.

TRIVIÑOS, A. N. S. Introdução à pesquisa em ciências sociais: a pesquisa qualitativa em educação. São Paulo: Atlas, 1987.

VELLOZO, D. P. M. Mulheres ao volante... - uma análise de gênero, saúde e trabalho em mulheres motoristas de ônibus na cidade do Rio de Janeiro. Dissertação de Mestrado. Rio de Janeiro, 2010.

Recebido em novembro de 2017

Aceito para publicação em abril de 2018 